\title{
Availability of metals to DGT devices with different configurations. The case of sequential $\mathrm{Ni}$ complexation
}

\author{
Jordi Sans-Duñó ${ }^{\mathrm{a}}$, Joan Cecilia ${ }^{\mathrm{b}}$, Josep Galceran ${ }^{\mathrm{a}}$, Jaume Puy ${ }^{\mathrm{a}, *}$ \\ a Departament de Química, Universitat de Lleida and AGROTECNIO-CERCA, Rovira Roure 191, 25198 Lleida, Spain \\ b Departament de Matemàtica, Universitat de Lleida and AGROTECNIO-CERCA, Rovira Roure 191, 25198 Lleida, Spain
}

\section{H I G H L I G H T S}

- Independent information is easily obtained with DGT devices with different thicknesses.

- Lability increases as the diffusive gel or the resin thickness increase.

- Simple expressions quantify the influence of the thickness on the availability.

- The formation of successive complexes reduces their availability.

- Speciation, mobilities and labilities of a mixture can be solved with a set of DGT data.

\section{A R T I C L E I N F O}

\section{Article history:}

Received 10 January 2021

Received in revised form 27 February 2021

Accepted 28 February 2021

Available online 8 March 2021

Editor: Damia Barcelo

\section{Keywords:}

DGT

Lability degree

Stoichiometry effects

Thickness of diffusion

Thickness of resin

NiNTA
G R A P H I C A L A B S T R A C T

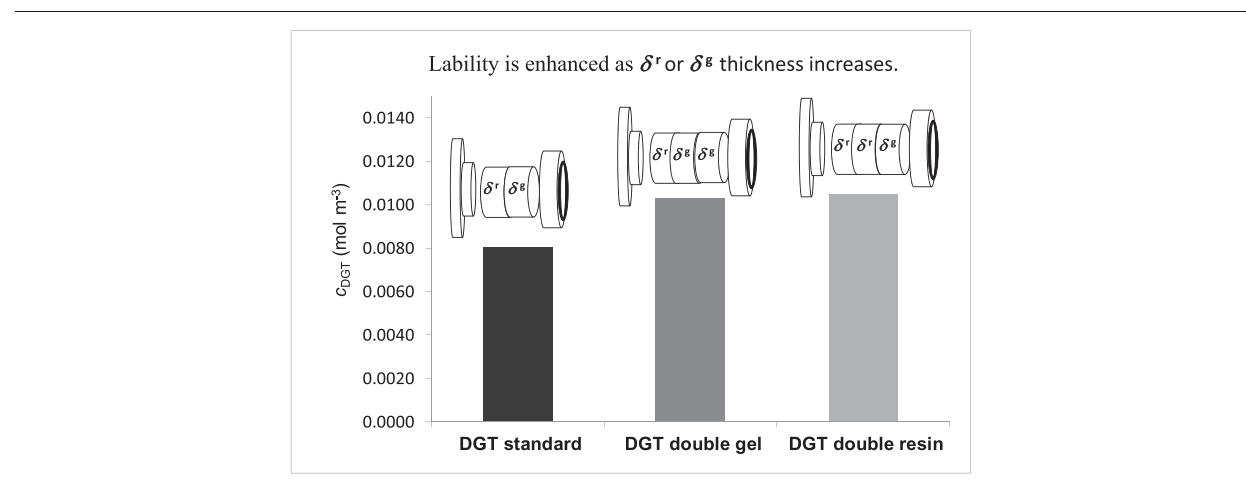

\begin{abstract}
A B S T R A C T
The analytical technique DGT (Diffusive Gradients in Thin-films) is able to gain access to a wealth of information by carefully interpreting accumulation data from passive samplers with different configurations (i.e. different thicknesses of its constituent layers). A set of DGT devices were simultaneously deployed in solutions of Ni and nitrilotriacetic acid (NTA) of different concentrations to measure the availability of Ni in these solutions. Accumulations indicate that the availability of Ni depends on both the thickness of the resin and the thickness of the diffusive gel. In both cases, the lability degree increases as the thickness increases. As the formation of successive complexes (such as $\mathrm{Ni}(\mathrm{NTA})_{2}$ ) proceeds, the availability of the metal decreases, which is quantitatively explained by reducing the formulation to a case with only one complex, but with an effective dissociation rate constant that decreases as the concentration of NTA increases. Simple analytical expressions are reported to quantify the lability degree in the different DGT configurations. These results indicate that a set of different DGT devices can characterize the availability of a cation in a natural sample with uptake processes at different spatial or time scales. Alternatively, and from a more fundamental point of view, information on speciation, mobilities and labilities of the species present in natural samples can be obtained with a set of DGT configurations.
\end{abstract}

(c) 2021 Elsevier B.V. All rights reserved.

\section{Introduction}

Despite many efforts, the measurement of trace metal speciation in freshwaters is still challenging. Different types of analytical techniques have been developed to gain insight into the equilibrium and dynamic

\footnotetext{
* Corresponding author.

E-mail address: jpuy@quimica.udl.cat (J. Puy).
}

speciation of natural waters. Some of them are based on quantifying the concentration of the free ion in solution, such as Ion selective electrodes, Absence of Gradients and Nersntian Equilibrium Stripping (AGNES) or the Donnan Membrane Technique (DMT) (Bakker and Pretsch, 2007; Companys et al., 2018; Lao et al., 2018; Parat and Pinheiro, 2015; Temminghoff et al., 2000). Alternatively, other techniques provide a quantification of a labile fraction, which includes the contribution of the free ion plus an extra contribution of some 
complexes. For example, the Gel Integrated Microelectrodes (GIME) were designed (Noel et al., 2003) to provide in situ measurements of some labile fraction of metal compounds able to dissociate in a welldefined diffusion layer. Anodic stripping voltammetry (ASV) and other stripping voltammetric techniques can also measure a labile fraction dependent on the electrode size (Cindric et al., 2020; Mikkelsen et al., 2006). Permeation Liquid Membrane (PLM) and Polymer Inclusion Membrane (PIM) also determine a labile fraction, but they can be tuned to reduce this fraction up to the concentration of the free ion (Gramlich et al., 2012; Parthasarathy et al., 2003; Vera et al., 2018).

It has been shown that the span of dynamic analytical techniques provides complementary data as a consequence of the spatiotemporal scale of the measurement process involved in each technique (van Leeuwen et al., 2005). These measurements can mimic the uptake of some nutrients or contaminants by living organisms, when the uptake process is selective for the free metal ion and evolves under diffusion-controlled conditions (Worms et al., 2006). Thus, chemical availabilities measured in a set of sensors can predict metal bioavailability to microorganisms and algae in natural media and they can be consistently used in pollution prevention laws and policies.

DGT (Diffusive Gradients in Thin-films) is a dynamic technique that is readily used for in situ measurements (Canovas et al., 2020; Davison and Zhang, 1994; Galceran and Puy, 2015; Menegario et al., 2017). It accumulates metals in a binding layer (resin disc) after they have diffused through a hydrogel (diffusive gel disc). The binding to the resin disc is ideally so fast and strong that perfect sink conditions apply (Levy et al., 2012b). The flux of metal bound is calculated from the metal accumulated during the whole deployment time, which is typically of the order of days and it constitutes a time weighted average concentration (Altier et al., 2016; Huang et al., 2016). Different chemical species can contribute to the accumulation, but DGT provides only an integrated value and it does not allow to identify the contribution of a specific species which depends on its mobility and lability. Lability refers to the capability of complexes to dissociate and reach local equilibrium along the diffusion domain (Galceran et al., 2001; Puy and Galceran, 2017). Net dissociation occurs in a region (the so-called reaction layer) where the complex concentration does not reach equilibrium with the free metal and ligand. In DGT, the reaction layer comprises part of the diffusive gel, but it extends into the resin domain where a negligible concentration of free metal drives partially labile complexes to dissociate (Mongin et al., 2011; Uribe et al., 2011). Thus, complexes are far more labile in DGT than in voltammetric sensors, where penetration into the electrode is not allowed. The dependence of the lability on the thickness of the diffusive and resin gels in DGT opens the way to obtain complementary information on the availability of a metal cation in a natural sample which can be summarized in a kinetic signature, i.e., a set of availabilities at different spatial and time scales covered by the set of sensors (Levy et al., 2012a; van Leeuwen et al., 2005). Furthermore, this information can be used to assess which are the complexes that contribute to the metal availability and, eventually, to determine the speciation, dissociation rate constants or diffusion coefficients of the species present in a natural sample (Warnken et al., 2008) which is an important task to understand the functioning of natural systems.

Up to now, there have been few attempts to determine mobilities, concentrations and labilities of the species present in a natural system (Baeyens et al., 2018; Gao et al., 2019; Levy et al., 2012a; Warnken et al., 2008). The procedure is based on using a set of DGT devices equipped with different gels and/or resins. A set of lability degrees for all the target analytes is, thus, obtained. These lability degrees can be written in terms of the speciation, physicochemical and geometrical parameters, when a convenient relationship is known. The resulting set of equations allow, then, to solve for the unknowns. An analytical expression, derived for a complex under ligand excess conditions is available (Uribe et al., 2011). In this paper, this expression is extended to consider electrostatic effects of the resin charge typical in freshwaters and it is applied to a model system that contains Ni and nitrilotriacetic (NTA) acid at different total NTA concentrations. One aim of this work is to check the accuracy of this expression in a controlled system, which is a necessary step prior to its application in natural samples. In many cases, complexes with a stoichiometric relationship between metal and ligand $1: n$ with $n>1$ arise. Despite such complexes being common for most ligands, they have seldom been considered in the DGT literature. Since Ni and NTA form a complex of stoichiometry $\mathrm{Ni}(\mathrm{NTA})_{2}$ at some concentration ratios, this situation is also considered in this paper, evidencing why trace metals become less available when successive complexes are formed.

\section{Chemical availability of metal cations in presence of ligands using DGT: the lability degree}

The lability degree, $\xi$, of a set of complexes of an element $M$ has been defined (Galceran et al., 2001; Puy and Galceran, 2017; Salvador et al., 2006b) as:

$\xi \equiv \frac{J-J_{\text {free }}}{J_{\text {labile }}-J_{\text {free }}}$

where $J$ stands for the flux of metal accumulated in the resin disc, and $J_{\text {free }}$ and $J_{\text {labile }}$ are defined below. $J_{\text {free }}$ is the flux due to the free metal in solution (as if complex dissociation was frozen), which in steadystate and perfect-sink conditions, as typically met in DGT deployments, becomes

$J_{\text {free }}=D_{\mathrm{M}} \frac{C_{\mathrm{M}}^{*}}{\delta^{g}}$

where $c_{\mathrm{M}}^{*}$ is the bulk concentration of free metal in solution, $D_{\mathrm{M}}$ is the metal diffusion coefficient, $\delta^{g}$ is the integrated thickness of the diffusive gel, filter and diffusive boundary layer (DBL), and common diffusion coefficients for each species are assumed to apply. When only one ligand is present in the solution, but successive complexes with stoichiometric relationships metal-to-ligand $1: 1, \ldots, 1: n$ can be formed, $J_{\text {labile }}$ is defined as:

$J_{\text {labile }}=\sum_{i=1}^{n} D_{\mathrm{ML}_{i}} \frac{c_{\mathrm{ML}_{i}}^{*}}{\delta^{g}}+J_{\text {free }}$

where $c_{\mathrm{ML} i}^{*}$ stands for the bulk concentration of the complex $\mathrm{ML}_{i}$ generated by one $\mathrm{M}$ ion and $i$ ligands (L) and $D_{\mathrm{ML} i}$ is its corresponding diffusion coefficient. Jlabile is the steady-state flux when dissociation of all the complexes is so fast that equilibrium with the free metal is reached at all the relevant spatial domain. Expression (3) can be extended to systems with different ligands by adding an extra summation for all the ligands present.

According to Eqs. (1)-(3), the lability degree of a system stands for the fraction that relates the actual contribution of complexes to the metal flux, $J-J_{\text {free }}$, with the maximum contribution, $J_{\text {labile }}-J_{\text {free, }}$, reached if all the complexes were labile (Galceran and Puy, 2015; Puy and Galceran, 2017).

The global lability degree of a set of complexes of an element in a system is experimentally accessible with Eq. (1) when the bulk concentrations and the diffusion coefficients are known. The particular lability degree of a given complex, $\xi_{\mathrm{ML}}$, is not experimentally accessible, since only the total accumulation is measurable. However, it is a measure of the complex consumption by dissociation and it can be defined (Uribe et al., 2013; Zhao et al., 2020) as

$\xi_{\mathrm{ML}_{i}} \equiv 1-\frac{c_{\mathrm{ML}_{i}}^{\mathrm{r}^{+}}}{c_{\mathrm{ML}_{i}}^{*}}$

where $c_{\mathrm{ML} i}^{\mathrm{r}}$ stands for the complex concentration at the diffusive gel side of the resin-diffusive gel interface $\left(x=\delta^{r}\right.$, see Fig. SI-1 in the Supporting Information). Obviously, $0 \leq \xi_{\mathrm{ML} i} \leq 1$. 
When only one complex is present, $\xi_{\mathrm{ML}}$ (we omit the subscript $i=1$, since it is no longer necessary) is given by Eq. (1), and when $J_{\text {free }} \ll$,

$\xi_{\mathrm{ML}}=\frac{J}{J_{\text {labile }}}=\frac{n_{\mathrm{M}} / A t}{D_{\mathrm{ML}}\left(\frac{\mathrm{cL}}{\delta^{g}}\right)}$

where $n_{\mathrm{M}}$ stands for the accumulation (moles) of metal M, $A$ is the area of the DGT device and $t$ the deployment time (Puy et al., 2014). Eq. (5) allows the measurement of the lability degree of ML complex in systems where only one relevant complex in solution is present.

Alternatively, in excess of ligand conditions, $\xi_{\mathrm{ML}}$ can be written in terms of physicochemical parameters (Puy et al., 2014) as:

$\xi=1-\frac{\left(1+\varepsilon K^{\prime}\right)}{\varepsilon K^{\prime}+\frac{\delta}{m} \operatorname{coth}\left(\frac{\delta^{g}}{m}\right)+\frac{\delta^{g} \Pi^{2} \mathrm{ML}\left(1+\varepsilon K^{\prime}\right)}{\lambda_{\mathrm{ML}}} \frac{D_{\mathrm{ML}}^{\mathrm{R}}}{D_{\mathrm{ML}}} \tanh \left(\frac{\delta^{\mathrm{r}}}{\lambda_{\mathrm{ML}}}\right)}$

where $\varepsilon=\frac{D_{\mathrm{ML}}}{D_{\mathrm{M}}}$ is the normalized diffusion coefficient. In Eq. (6), $z_{\mathrm{ML}}$ stands for the charge of the ML complex,

$m=\sqrt{\frac{D_{\mathrm{ML}}}{k_{\mathrm{d}}\left(1+\varepsilon K^{\prime}\right)}}$

$\lambda_{\mathrm{ML}}=\sqrt{\frac{D_{\mathrm{ML}}^{\mathrm{R}}}{k_{\mathrm{d}}}}$

$\Pi^{z_{\mathrm{ML}}}=\frac{c_{\mathrm{ML}}^{\mathrm{r}^{-}}}{c_{\mathrm{ML}}^{\mathrm{r}^{+}}}=\exp \left(\frac{z_{\mathrm{ML}} F \Psi}{R T}\right)$

$R$ and $F$ label the gas and the Faraday constants, respectively, $T$ labels the temperature and $\Psi$ stands for the electrostatic potential difference between the diffusive gel and the resin.

From now on, the superscript $R$ denotes the value of a magnitude in the resin domain, while the absence of this superscript denotes magnitudes in diffusion domains other than the resin disc. Thus, $D_{\mathrm{ML}}^{R}$ labels the diffusion coefficient in the resin domain (we are interested in allowing different diffusion coefficients in the resin and diffusive gel domains as we will see later on), $K=\frac{k_{a}}{k_{\mathrm{d}}}$ stands for the stability constant, $K^{\prime}=\frac{k_{\mathrm{a}} c_{\mathrm{L}}^{*}}{k_{\mathrm{d}}}=$ $\frac{k_{\mathrm{a}}^{\prime}}{k_{\mathrm{d}}}=\frac{c_{\mathrm{ML}}^{*}}{c_{\mathrm{M}}^{*}}$ and $k_{\mathrm{a}}$ and $k_{\mathrm{d}}$ are the association and dissociation rate constants.

The Boltzmann factor $\Pi$ stands for the electrostatic partitioning of a monovalent positively charged species at the resin/diffusive gel interface, due to the negative charge of the resin. This effect implies that the concentration profiles of charged species at the resin-diffusive gel interface suffer a discontinuity which depends on the ionic strength and the charge of the species (Pommier et al., 2021; Puy et al., 2014).

Eq. (6) indicates that the lability degree depends on the ligand concentration as well as on the geometrical parameters of the DGT device, increasing when $\delta^{\mathrm{g}}$ or $\delta^{\mathrm{r}}$ increase. The lability degree decreases as the ligand concentration increases, since this increase shifts the equilibrium of complexation towards association. However, in DGT devices most of the metal bound to the resin comes from the complex dissociation inside the resin domain where, under perfect sink conditions, the free metal concentration is negligible (Puy et al., 2016; Puy et al., 2012), but where the complexes that are not fully labile can have a relevant concentration. Since the shift of the equilibrium as the ligand concentration increases cannot take place in absence of metal, the lability degree in DGT devices becomes almost independent of the ligand concentration in ligand excess conditions.

In a system that contains a mixture of ligands, $\xi_{\mathrm{ML}}$ differs from the corresponding value in a single ligand system sharing in common the complex and free ligand concentrations, $\xi_{\mathrm{ML}}^{h=1}$. However, the use of $\xi_{\mathrm{ML}}^{h=1}$ measured in single ligand systems provides reasonably approximate values when predicting metal accumulation in mixtures (Altier et al.,
2018; Uribe et al., 2013) due to opposite mutual effects that tend to cancel.

\section{Materials and methods}

\subsection{Experimental set-up for DGT measurements}

Diffusive and resin gels were acquired from DGT research Limited (https://www.dgtresearch.com). A total number of 15 DGT devices were used. In order to assay DGT devices with different resin and diffusive gel thickness, 5 groups of 3 units were prepared containing: 1 filter, 1 diffusive gel and 1 resin disc (labelled as configuration 1R1G); 1 filter, 1 diffusive gel and 2 resin discs (2R1G); 1 filter, 2 diffusive gels and 1 resin disc (1R2G) and 3 filters, 1 diffusive gel and 1 resin disc (1R1G3F). A last group containing 1 filter, 1 diffusive gel and 1 resin disc was used for blank measurements.

DGT holders (piston type, $2 \mathrm{~cm}$ diameter window), polyacrylamide gel discs (diffusive disc, $0.779 \mathrm{~mm}$ thick and resin disc $0.4 \mathrm{~mm}$ thick) and polyethersulfone (PES) filters $(0.45 \mu \mathrm{m}$ pore size, $150 \mu \mathrm{m}$ thick) were used. Once assembled, they were rinsed in a preconditioning solution at the same ionic strength $\left(100 \mathrm{mmol} \mathrm{L}^{-1}\right)$ of the solutions for at least $24 \mathrm{~h}$.

Deployments: 2 L of solutions corresponding to the experimental conditions of either column 1 (Exp A) or column 2 (Exp B) of Table 1 were left to equilibrate in a $5 \mathrm{~L}$ polyethylene exposure bucket thermostatized at $25{ }^{\circ} \mathrm{C}$ during $3 \mathrm{~h}$ and stirring rate $240 \mathrm{rpm}$. Three DGT devices of each type were deployed in each solution (see working conditions in Table 1). Deployment time lasted for $20 \mathrm{~h}$ and $\mathrm{pH}$ was measured at the beginning and end of the accumulation. Three aliquots of $0.9 \mathrm{~mL}$ were extracted from the solution before and after the deployment in order to measure total Ni concentration with ICP-MS (7700 Series, Agilent).

After the deployment, DGT devices were disassembled, resin discs were extracted using clean tweezers and eluted using $1 \mathrm{~mL} \mathrm{HNO}_{3} 20 \%$, to ensure an efficient metal extraction procedure (elution factor equal to 1 was used). More details are described elsewhere (Altier, 2018).

\subsection{Experimental set-up for measurements with diffusion cell}

Stock solutions of $\mathrm{Ni}\left(\mathrm{Ni}\left(\mathrm{NO}_{3}\right)_{2} \cdot 6 \mathrm{H}_{2} \mathrm{O}\right.$, Sigma-Aldrich, puriss p.a.) $100 \mathrm{mmol} \mathrm{L}^{-1}$, NTA (Fluka, analytical grade) $0.30 \mathrm{mmol} \mathrm{L}^{-1}$, HEPES (4-(2-hydroxyethyl)-1-piperazineethanesulfonic acid), high purity grade Amresco, at pH 8.4, adjusted by dropwise addition of $10^{3} \mathrm{mmol} \mathrm{L}^{-1}$ $\mathrm{NaOH}$ or $\mathrm{HNO}_{3}$ (Fluka ACS reagent) $250 \mathrm{mmol} \mathrm{L}{ }^{-1}$ and glycine(SigmaAldrich, puriss. p.a) $25 \mathrm{mmol} \mathrm{L}^{-1}$ were prepared. Solutions were left to equilibrate for $24 \mathrm{~h}$ with stirring and $T=24.9^{\circ} \mathrm{C}$. In experiment 4 (Table 2), glycine was used instead of HEPES due to its buffer capacity in a different $\mathrm{pH}$ range (Mohan, 2003).

A set of four experiments were done in a diffusion cell to measure the diffusion coefficients of NiNTA and $\mathrm{Ni}(\mathrm{NTA})_{2}$ across the diffusive gel. The two compartments (donor and acceptor) of the diffusion cell were connected through a diffusive gel placed in the communication

Table 1

Total concentrations of Ni, NTA, HEPES and physical parameters for DGT experiments Exp A and Exp B.

\begin{tabular}{lll}
\hline & Exp A & Exp B \\
\hline$c_{\mathrm{T}, \mathrm{Ni}}\left(\mathrm{mmol} \mathrm{L}^{-1}\right)$ & $3.50 \times 10^{-2}$ & $3.50 \times 10^{-2}$ \\
$c_{\mathrm{T}, \mathrm{NTA}}\left(\mathrm{mmol} \mathrm{L}^{-1}\right)$ & $5.50 \times 10^{-2}$ & 1.14 \\
$\mathrm{HEPES}_{\left(\mathrm{mmol} \mathrm{L}^{-1}\right)}$ & 0.200 & 0.200 \\
$\mathrm{NaNO}_{3}\left(\mathrm{mmol} \mathrm{L}^{-1}\right)$ & 100 & 100 \\
$\mathrm{pH}$ & 7.7 & 7.6 \\
$T\left({ }^{\circ} \mathrm{C}\right)$ & 25 & 25 \\
$\% \mathrm{NiNTA}$ & $99 \%$ & $62 \%$ \\
$\% \mathrm{Ni}(\mathrm{NTA})_{2}$ & $1 \%$ & $38 \%$
\end{tabular}


Table 2

Experimental conditions (for experiments 1 to 4 ) which have been employed in donor and acceptor diffusion cells respectively

\begin{tabular}{|c|c|c|c|c|c|c|c|c|}
\hline \multirow[t]{2}{*}{ Parameters } & \multicolumn{4}{|l|}{ Donor } & \multicolumn{4}{|c|}{ Acceptor } \\
\hline & Exp 1 & Exp2 & Exp 3 & Exp 4 & Exp 1 & Exp 2 & Exp 3 & Exp 4 \\
\hline$c_{\mathrm{T}, \mathrm{Ni}}\left(\mathrm{mmol} \mathrm{L}^{-1}\right)$ & $5.69 \times 10^{-2}$ & $4.6 \times 10^{-2}$ & $1 \times 10^{-2}$ & $3.77 \times 10^{-2}$ & - & - & - & - \\
\hline$c_{\mathrm{T}, \mathrm{NTA}}\left(\mathrm{mmol} \mathrm{L}^{-1}\right)$ & - & $5 \times 10^{-2}$ & $1 \times 10^{-1}$ & - & - & - & - & - \\
\hline$c_{\mathrm{T}, \text { Hepes }}\left(\mathrm{mmol} \mathrm{L}^{-1}\right)$ & 0.2 & 0.2 & - & 0.2 & 0.2 & 0.2 & - & 0.2 \\
\hline$c_{\mathrm{T}, \text { Glycine }}\left(\mathrm{mmol} \mathrm{L}^{-1}\right)$ & - & - & $1 \times 10^{-1}$ & - & - & - & $1 \times 10^{-1}$ & - \\
\hline$c_{\mathrm{NaNO}_{3}}\left(\mathrm{mmol} \mathrm{L}^{-1}\right)$ & 100 & 100 & 100 & 100 & 100 & 100 & 100 & 100 \\
\hline $\mathrm{pH}$ & 7.44 & 7.60 & 8.66 & 7.04 & 7.42 & 7.48 & 8.87 & 6.97 \\
\hline$T\left({ }^{\circ} \mathrm{C}\right)$ & 24.9 & 24.9 & 24.9 & 24.9 & 24.9 & 24.9 & 24.9 & 24.9 \\
\hline Volume (L) & 0.100 & 0.088 & 0.100 & 0.092 & 0.100 & 0.088 & 0.100 & 0.092 \\
\hline Total time (s) & 11,700 & 10,380 & 10,320 & 11,460 & 11,700 & 10,380 & 10,320 & 11,460 \\
\hline
\end{tabular}

$2 \mathrm{~cm}^{2}$ circular hole. See experimental details in the SI. Concentrations of the solutions are gathered in Table 2. The acceptor cell contains the buffer and background electrolyte at the same concentrations as the corresponding donor solution in the experiment. In all experiments, sodium nitrate (Fluka, puriss. p.a.) was used as background electrolyte to reach an ionic strength $I=100 \mathrm{mmol} \mathrm{L}^{-1}$.

\subsection{Determination of diffusion coefficients}

Diffusion coefficients were determined from the measurement of the slope of the plot of the mass of $\mathrm{Ni}$ in the acceptor solution of the diffusion cell against time (Scally et al., 2006; Shiva et al., 2015). The mass of $\mathrm{Ni}$ in the acceptor solution was determined by analysing at different times aliquots of the acceptor solution with ICP-MS, resulting in a linear increase with time as reported in the SI. Assuming: i) that the concentrations of M and ML in the acceptor are at any time negligible with respect to those in the donor solution, ii) a common diffusion coefficient for each species in water and gel solutions and iii) steady-state diffusion, then the mass of metal in the acceptor solution, $n_{\mathrm{M}}$, can be written as:

$n_{\mathrm{M}}=\frac{\sum_{i}^{n} D_{\mathrm{ML}_{i}} c_{\mathrm{ML}_{i}}^{*}}{\delta^{g}+\delta^{\mathrm{DBL}}} A t$

where $\delta^{\mathrm{DBL}}$ stands for the total DBL thickness at both sites of the diffusive gel, so that in this previous formula $\delta^{g}$ stands just for the gel thickness.

For $n=2$, at least two experiments are required to determine $D_{\mathrm{ML}}$ and $D_{\mathrm{ML} 2}$. Total concentrations of the performed experiments are detailed in Table 2. Concentrations of $c_{\mathrm{ML}}^{*}$ and $c_{\mathrm{ML} 2}^{*}$ were calculated using the speciation software VMinteq (Gustafsson, 2016). The parameter $\delta^{\mathrm{DBL}}$ was determined from an experiment with only free metal, also included in Table 2, using $D_{\mathrm{Ni}}=5.77 \times 10^{-10} \mathrm{~m}^{2} \mathrm{~s}^{-1}$ as reported by DGT Research. The mass of $\mathrm{Ni}$ in the acceptor solution, $n_{\mathrm{M}}$, was determined by analysing samples with ICP-MS from both diffusion cell compartments, see Table 2. Exp 4 (see Table 3) was used to verify the Ni diffusion coefficient in a stack of two diffusive gels. See SI for more details.

\subsection{Determination of the lability degree of the Ni complexes in the different DGT devices}

When there are two relevant $\mathrm{Ni}$ complexes in the sample solution (Exp B in Table 1), $62 \%$ of NiNTA and $38 \%$ of $\mathrm{Ni}(\mathrm{NTA})_{2}$, the global lability

Table 3

Experimental diffusion coefficients and the regression coefficient obtained in this work from the number of accumulated moles $v$ s. time, using the conditions of Table 2.

\begin{tabular}{lll}
\hline Experiment & $\begin{array}{l}\text { Diffusion coefficient in the gel } \\
\text { phase (in } \mathrm{m}^{2} \mathrm{~s}^{-1} \text { ) }\end{array}$ & $\mathrm{R}^{2}$ \\
\hline Exp 2 & $D_{\mathrm{NiNTA}}=5.06 \times 10^{-10}$ & 0.9996 \\
Exp 3 & $D_{\mathrm{Ni}(\mathrm{NTA}) 2}=2.25 \times 10^{-10}$ & 0.9976 \\
Exp 4 (using 2 diffusion gels) & $D_{\mathrm{Ni}}=4.60 \times 10^{-10}$ & 0.9989 \\
\hline
\end{tabular}

degree of Ni complexes in the different DGT devices is assessed with Eq. (1) (theoretically estimating $J_{\text {labile }}$ with Eq. (3) and $J_{\text {free }}$-which becomes negligible- with Eq. (2)). When only one Ni complex is present (Exp A in Table 1, 99\% of Ni as NiNTA), the lability degree is computed with the particular Eq. (5). In both cases, speciation is estimated with VMinteq and the diffusion coefficients are determined as described in Section 3.3. The thickness of the diffusion domain is particular for each DGT configuration. The thickness of an individual diffusive gel, resin and filter are $0.629 \mathrm{~mm}, \delta^{r}=0.4 \mathrm{~mm}$ and $\delta^{\mathrm{f}}=0.150 \mathrm{~mm}$, respectively. Due to the vigorous stirring, the DBL thickness in DGT experiments is neglected.

\subsection{Determination of kinetic constants}

In Exp A (Table 1), NiNTA is the only relevant Ni species. In order to evaluate whether Eq. (6) accurately predicts the lability degree of the NiNTA in the different DGT devices and different concentrations, we need to estimate the dissociation rate constant of the NiNTA. In this task, the experimental value of $\xi_{\text {NinTA }}$ for 1 R1G devices is used as input value and solving Eq. (6), with an iterative procedure described in the SI, $k_{\mathrm{d}, 1}$ (for NiNTA dissociation) is obtained.

Notice that using $\xi_{\text {NiNTA }}$ from 1R1G DGT, instead of that from other geometrical configurations, is an arbitrary choice, but it has been checked that using $\xi_{\text {NiNTA }}$ from other DGT configurations as an input, a very close output $k_{\mathrm{d}, 1}$ is retrieved, which suggests the suitability of $\xi_{\text {NiNTA }}$ given by Eq. (6).

In Exp B, both NiNTA and $\mathrm{Ni}(\mathrm{NTA})_{2}$ concentrations are relevant and the values of $k_{\mathrm{a}, 1}, k_{\mathrm{d}, 1}, k_{\mathrm{a}, 2}$, and $k_{\mathrm{d}, 2}$ are required to run the numerical simulations (see next section). $k_{\mathrm{a}, i}$ and $k_{\mathrm{d}, i}$ label, respectively, the association and dissociation rate constants of the process $\mathrm{ML}_{i-1}+\mathrm{L} \rightleftharpoons \mathrm{ML}_{i}$.

In general, in a set of successive complexes, the dissociation of ML into $\mathrm{M}$ and L is usually the rate limiting step (Morel and Hering, 1993; Puy et al., 2004). Assuming that the dissociation of ML is the rate limiting step, $\mathrm{ML}$ and $\mathrm{ML}_{2}$ will be in equilibrium along all the spatial domain, but not with $\mathrm{M}$. The particular values of the rate constants $k_{\mathrm{a}, 2}$ and $k_{\mathrm{d}, 2}$ are, then, not necessary whenever their ratio fulfils the stability constant of $\mathrm{Ni}(\mathrm{NTA})_{2}$ (which was taken from VMinteq) and are large enough for the concentrations of both NiNTA and Ni(NTA $)_{2}$ to satisfy equilibrium. Accordingly, a dissociation rate constant for $\mathrm{ML}_{2}$ higher than 100 -fold that of ML was used after checking that a further increase did not modify the accumulation, securing that the rate limiting step is the ML dissociation process.

\subsection{Numerical simulation of concentration profiles and accumulations}

A further step in the quantitative understanding of the system behaviour has been gained by using a rigorous numerical code, that solves the system of diffusion-reaction equations taking into account the specific DGT initial and boundary conditions, to obtain theoretical expected values of the lability degree (see details in Section 1 of this SI or Section 2 in the SI of reference (Jimenez-Piedrahita et al., 2015)). 


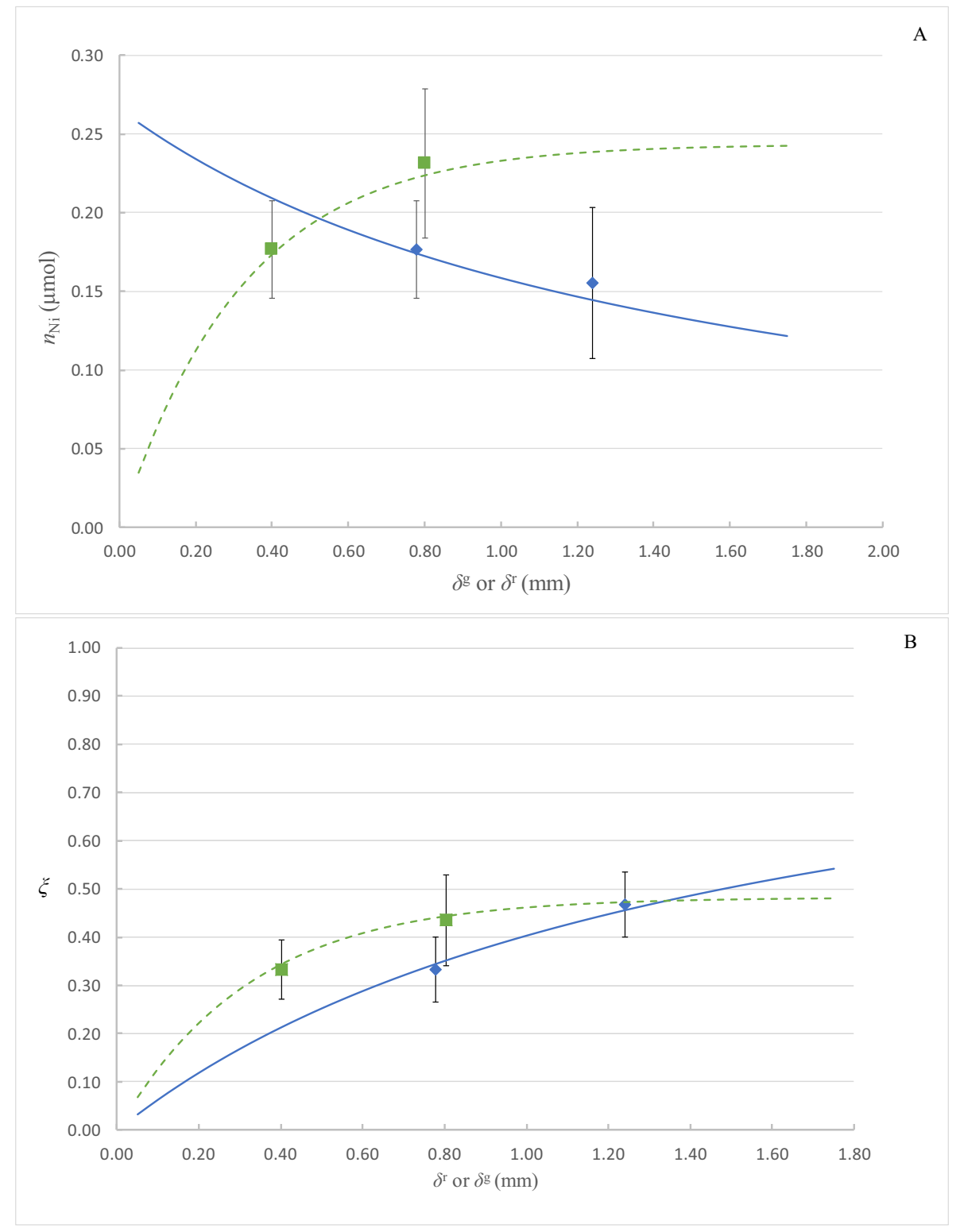

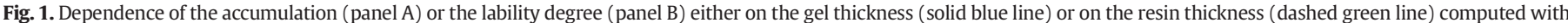

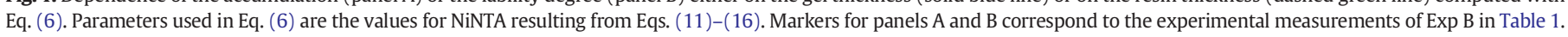

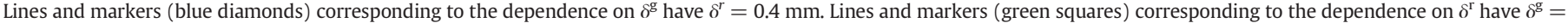
$0.779 \mathrm{~mm}$. Errors bars correspond to standard deviations of accumulation (A) or lability degree (B) as reported in Table 4.

Speciation calculations with VMinteq for total Ni and NTA concentrations of each case indicate that Ni, NiNTA, Ni(NTA $)_{2}$, NTA and HNTA are the relevant species, while the rest of species have negligible concentrations (see Section 4 of the SI). Accordingly, only these relevant species have been considered in the numerical simulation code. Rate constants and diffusion coefficients determined as commented above were used. Notice that the acid base equilibrium NTA $+\mathrm{H} \rightleftharpoons \mathrm{HNTA}$ is included in the simulation considering equilibrium between these

Table 4

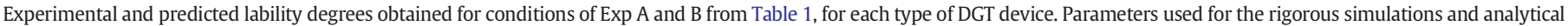
calculations as in Fig. 2.

\begin{tabular}{|c|c|c|c|c|c|c|c|c|}
\hline \multirow[t]{2}{*}{ Geometrical configuration } & \multicolumn{4}{|c|}{$c_{\mathrm{T}, \mathrm{NTA}}=5.5 \times 10^{-2} \mathrm{mmol} \mathrm{L}^{-1}(\operatorname{Exp~A})$} & \multicolumn{4}{|c|}{$c_{\mathrm{T}, \mathrm{NTA}}=1.15 \mathrm{mmol} \mathrm{L}^{-1}(\operatorname{Exp~B})$} \\
\hline & $1 \mathrm{R} 1 \mathrm{G}$ & 2R1G & $1 \mathrm{R} 2 \mathrm{G}$ & 1R1G3F & 1R1G & 2R1G & $1 \mathrm{R} 2 \mathrm{G}$ & 1R1G3F \\
\hline$n_{\mathrm{Ni}}(\mu \mathrm{mol})$ & 0.26 & 0.28 & 0.24 & 0.16 & 0.18 & 0.23 & 0.13 & 0.15 \\
\hline Standard deviation $\left(n_{\mathrm{Ni}}(\mu \mathrm{mol})\right)$ & 0.04 & 0.05 & - & 0.02 & 0.03 & 0.05 & - & 0.05 \\
\hline Experimental $\xi$ & 0.46 & 0.55 & 0.72 & 0.49 & 0.35 & 0.46 & 0.56 & 0.49 \\
\hline Standard deviation (experimental $\xi$ ) & 0.08 & 0.09 & - & 0.06 & 0.06 & 0.09 & - & 0.15 \\
\hline Predicted $\xi$ (simulation) & 0.44 & 0.53 & 0.63 & 0.55 & 0.38 & 0.48 & 0.57 & 0.49 \\
\hline Predicted $\xi$ (analytical Eq. (6)) & 0.45 & 0.55 & 0.60 & 0.57 & - & - & - & - \\
\hline Predicted $\xi$ (analytical Eqs. (6), (11)-(15)) & - & - & - & - & 0.39 & 0.50 & 0.59 & 0.51 \\
\hline
\end{tabular}


species. Association and dissociation kinetic constants for the proton binding to the NTA are then assumed large enough, while the ratio fulfils the equilibrium constant.

In conditions of low ionic strength, the negative charge of the resin can induce a migration flux resulting from the gradient of the electrical potential at the resin-gel interface. In the simulation code, this physical phenomenon is modelled using the Donnan partition model which considers the electrical potential as a step function located at the resin-gel interface (See Section 1 of the SI). Accordingly, a Boltzmann factor ( as defined in Eq. (9) is considered for the electrostatic partitioning of the charged species. The Boltzmann factor for each species was evaluated from the experimental determination of the rubidium Boltzmann factor. Rubidium chloride was added into the solution at a concentration of $3.92 \times 10^{-3} \mathrm{mmol} \mathrm{L}^{-1}$. and because the specific binding of $\mathrm{Rb}$ to the resin sites is expected to be negligible, as other alkali metals such as $\mathrm{Na}$, all the $\mathrm{Rb}$ mass eluted from the resin disc corresponds to the electrostatic binding. Accordingly, the Boltzmann factor for $\mathrm{Rb}$ can be computed dividing the bulk $\mathrm{Rb}$ concentration by the concentration of rubidium in the resin disc as Eq. (9) indicates (Altier et al., 2016; Yezek and van Leeuwen, 2005). For any other species with charge $z_{i}$, the factor $(\Pi)^{z_{i}}$ applies.

\section{Results and discussion}

\subsection{Characterization of the solutions described in Table 1}

The first experiment detailed in Table $2(\operatorname{Exp} 1)$ aims to calculate $\delta^{\text {DBL }}$ in the diffusion cell. This calculation uses the tabulated value $5.77 \times 10^{-10} \mathrm{~m}^{2} \mathrm{~s}^{-1}$ from DGT research limited (https://www. dgtresearch.com/diffusion-coefficients) for $D_{\mathrm{Ni}}$ at $25^{\circ} \mathrm{C}$. Once $\delta^{\mathrm{DBL}}$ is known, Eq. (10) allows the determination of $D_{\mathrm{NiNTA}}$ and $D_{\mathrm{Ni}(\mathrm{NTA})_{2}}$ from the rest of experiments. Diffusion coefficients of NiNTA and Ni(NTA $)_{2}$ measured with the diffusion cell are reported in Table 3. The obtained diffusion coefficient of $\mathrm{Ni}(\mathrm{NTA})_{2}$ is smaller than that of NiNTA indicating an increase of the size of the Ni(NTA $)_{2}$ complex. Exp 4 in Table 2 also allows the determination of the Ni diffusion coefficient in a stack of two diffusive gels. The diffusion coefficient is expected to be independent of the thickness of the diffusive gel, but the experimental measurement yielded $D_{\mathrm{Ni}}=4.60 \times 10^{-10} \mathrm{~m}^{2} \mathrm{~s}^{-1}$, a value lower than the tabulated value at DGT research limited, indicating that a kind of extra resistance to diffusion appears when a stack of diffusive gels is used. We speculate that this extra resistance might be due to a change in the size of the gel pores at the surface of the gel.

The Boltzmann factor for the Donnan partitioning at the resin diffusive gel interface, obtained by adding $\mathrm{Rb}$ into the system was $\Pi=1.13$, which is a small value, indicating an important screening of the resin charges by the salt background. However, species with electrical charge $z_{i}$ will have Boltzmann factors $\Pi^{z_{i}}$. Since Ni(NTA) $)_{2}$ and NTA have a high electrical charge ( -4 and -3 , respectively) the resulting Boltzmann factors for these species are non-negligible (1.6 and 1.4, respectively) advising the explicit consideration of the electrostatic effects. These Boltzmann factors can be applied to all experiments of Table 1, since they share a common ionic strength and $\mathrm{pH}$.

The dissociation rate constant of NiNTA, fitted with the numerical simulation from the experimental lability degree in Exp A (Table 1), is $k_{\mathrm{d}, 1}=1.43 \times 10^{-3} \mathrm{~s}^{-1}$.

\subsection{Dependence of the accumulation and lability degree on the geometrical parameters of the DGT device}

Fig. 1 plots the accumulation and the lability degree $v s$. the thickness of the diffusive gel or the thickness of the resin gel. The lines in Fig. 1 correspond to values computed with Eq. (6) for a complex whose diffusion coefficient, stability and rate dissociation constant coincide with the above values determined for NiNTA. As shown in Fig. 1a, an increase of $\delta^{\mathrm{g}}$ decreases the accumulation, since the diffusion domain becomes thicker, the source of complex moves away and the flux decreases. Conversely, an increase of $\delta^{\mathrm{r}}$ increases the accumulation, since the complexes NiNTA and $\mathrm{Ni}(\mathrm{NTA})_{2}$ inside the resin have more time and volume for dissociation.

Fig. $1 \mathrm{~b}$ depicts the dependence of the lability degree on the thickness of the diffusive gel or the thickness of the resin gel. As seen in the figure, an increase of either $\delta^{\mathrm{r}}$ or $\delta^{\mathrm{g}}$ increases $\xi$. However, the influence of $\delta^{\mathrm{r}}$ is more pronounced at low thicknesses, but it plateaus beyond a certain resin thickness, while a sufficiently large increase of $\delta^{g}$ is able to bring the complex to full lability. Indeed, an increase in $\delta^{\mathrm{r}}$ increases the dissociation volume of the complexes that have penetrated into the resin, while the complex concentration profile has not reached full dissociation in the resin domain yet. When full dissociation is reached, a further increase of $\delta^{\mathrm{r}}$ has no effect neither on the lability degree nor on the accumulation. Thus, the lability degree is not an intrinsic property of a complex, since it also depends on the geometrical characteristics of the sensor, among other factors, as Eq. (6) indicates.

Experimental $\xi$-values measured with DGT devices of different geometrical characteristics for the Ni complexes in the solutions described in Table 1 are reported in Table 4. These values corroborate the increase of $\xi$ as either $\delta^{\mathrm{r}}$ or $\delta^{\mathrm{g}}$ increase. Table 4 also gathers the theoretical prediction of $\xi$-values obtained with numerical simulations as indicated in Section 3.6. Notice the agreement between experimental measurements and numerical simulation predictions, indicating that, despite its simplicity, the model contains an essentially correct description of the main physicochemical phenomena in DGT devices.

We aim at checking whether Eq. (6) is useful in the prediction of the lability degree for different thicknesses of the diffusive or resin gels. Eq. (6) can only be directly applied to the system with $c_{\mathrm{T}, \mathrm{NTA}}=$ $5.5 \times 10^{-2} \mathrm{mmol} \mathrm{L}^{-1}$, since in this solution, NiNTA is the only one relevant Ni complex and the simple scheme $\mathrm{M}+\mathrm{L} \rightleftharpoons \mathrm{ML}$ linked to Eq. (6) applies. The predicted $\xi$-values for all the DGT configurations used in Exp A are close to the experimental measurements and to the numerical simulation values.

Eq. (6) was obtained as an analytical solution of the reactiondiffusion problem assuming excess of ligand. In this approximation, the concentration profile of the ligand is expected to be flat. Fig. 2 depicts the simulated concentration profiles in DGT devices of the Ni complexes of the solution described in column 1 of Table 1 (Exp A). The discontinuities of electrically charged species at $x=\delta^{\mathrm{r}}$ are due to the Donnan partitioning, so that the size of the discontinuity depends on $(\Pi)^{z_{i}}$ where $z_{i}$ labels the electrical charge of the species. However, besides the discontinuity, Fig. 2 shows that $c_{\mathrm{L}}(x)$ increases as $x$ decreases, indicating that the ligand produced by dissociation of the complex at the resin domain is not negligible with respect to the ligand in the bulk solution. Thus, ligand excess conditions are not strictly fulfilled and accordingly, we are not in the best situation for using Eq. (6). However, even in this case, its predictions of $\xi$ are quite accurate, since the NTA concentration is buffered by the presence of HNTA as the main NTA species and most of the NTA produced by dissociation is transformed into HNTA to diffuse back to the bulk solution.

Furthermore, in Fig. 2, Ni and NiNTA are in equilibrium along most of the diffusive gel (for instance for $x>0.47 \mathrm{~mm}$ in Fig. 2A). However, close to the resin interface, the metal concentration drops to zero, while the complex cannot reach equilibrium, since dissociation is not fast enough. This is the so-called reaction layer, which extends also to all the resin domain, where a negligible concentration of $\mathrm{Ni}$ coexists with a non-negligible NiNTA concentration. It is in the reaction layer where net dissociation occurs, while just net diffusion takes place in the rest of the diffusion domain.

Fig. 2 also offers an overview of how steady-state concentration profiles of the species in the DGT device evolve with the thickness of the diffusive or the resin gels. This overview is useful to understand the dependence of the lability degree on these geometrical characteristics. Indeed, according to Eq. (5), $\xi_{\mathrm{NiNTA}}$ is just the distance from the normalized NiNTA profile at $x=\delta^{\mathrm{r}}$ up to 1 . The effect 

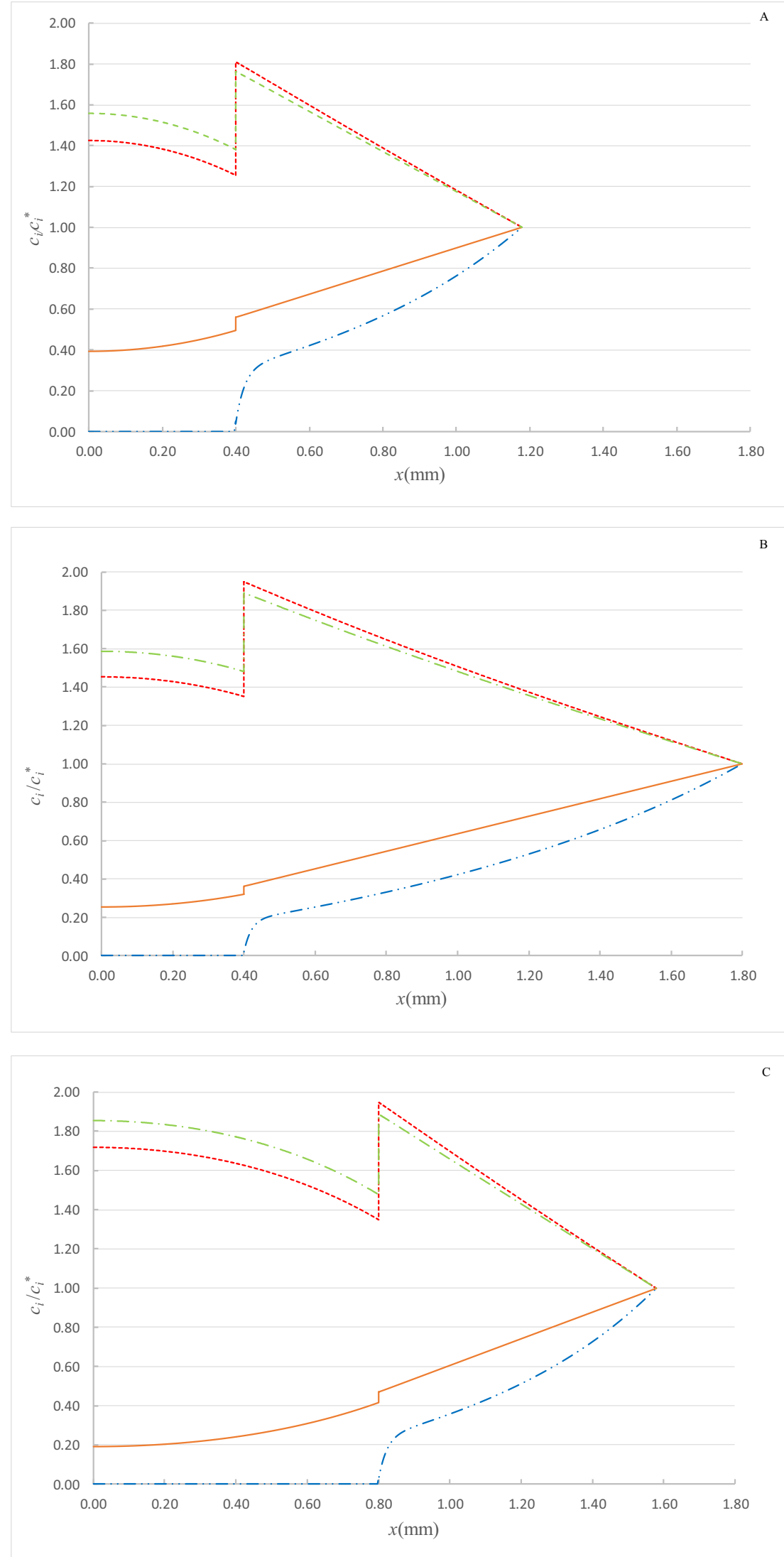

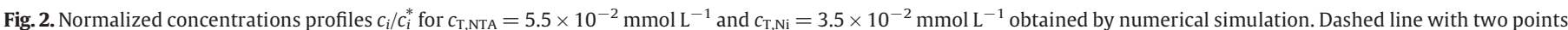

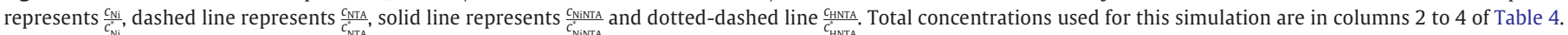

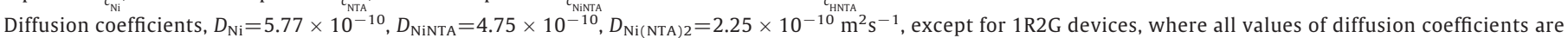

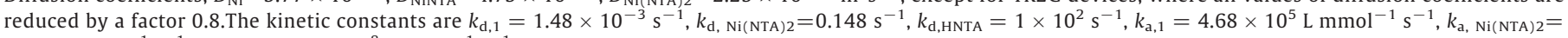
$9.635 \mathrm{~L} \mathrm{mmol}^{-1} \mathrm{~s}^{-1}, k_{\mathrm{a}, \mathrm{HNTA}}=4.46 \times 10^{8} \mathrm{~L} \mathrm{mmol}^{-1} \mathrm{~s}^{-1}$ and $\Pi=1.13$. 
of $\delta^{g}$ can be assessed by comparing Fig. 2A with Fig. 2B. In steady state, the flux of the complex dissociation in the resin domain should equal the flux of the complex entering into the resin domain, i.e., the flux of complex crossing the resin-diffusive gel interface. As a first approximation, we can assume that the profile of NiNTA is approximately flat inside the resin and linear in the diffusive gel domain, with slope $\xi / \delta^{\mathrm{g}}$ as seen in the figure. For a given $\delta^{\mathrm{r}}$, an increase of $\delta^{\mathrm{g}}$ implies a decrease of the slope of the NiNTA in the diffusive gel. Accordingly, the flux of NiNTA entering into the resin domain will decrease, and to keep steady state, the amount of NiNTA dissociated in the resin domain must also decrease by decreasing the concentration of NiNTA in the resin domain. Likewise, an increase of $\delta^{\mathrm{r}}$ increases the capacity of dissociation in the resin domain requiring an increased flux supply of NiNTA to reach steady state and a lower value of the normalized concentration profile at the resin-diffusive gel interface (compare Fig. 2A with Fig. 2C).

The prediction of the lability degree in Exp B goes parallel to the discussion of the influence of the NTA concentration on the lability degree and it is reported in the next section.

\subsection{Dependence of the lability degree on the NTA concentration}

The dependence of the lability degree of a complex on the ligand concentration is relevant to assess the influence of the composition on the availability of toxic or nutritive elements in natural media. It has been reported that increasing the ligand concentration, the lability degree of a complex decreases, since the dissociation equilibrium is shifted towards association. However, the availability of a metal in DGT devices under ligand excess conditions is mainly due to the complex dissociation in the resin domain (Puy et al., 2012). As the concentration of free metal in the resin domain is negligible, in the typical case where the metal is strongly and quickly bound to the resin, the complexation equilibria cannot be shifted by an increase of the ligand concentration and the availability of the metal becomes almost independent of the ligand concentration in the DGT devices. This result facilitates the determination (or estimation) of the lability degree of a complex in DGT devices, since it allows the use of any ligand concentration in the measurement system just with the proviso of being under ligand excess conditions.
When the free ligand concentration is below that of the free metal, a decrease of the ligand concentration also decreases the lability degree against the expected general trend commented above (Altier et al., 2018).

However, other changes associated to an increase of the ligand concentration can concomitantly take place. Indeed, as seen in Table 2 and in Fig. 3, when the total NTA concentration increases (Exp B), the bulk speciation indicates a very relevant increase of $\mathrm{Ni}(\mathrm{NTA})_{2}$.

Table 4 shows the experimental lability degree of the Ni complexes. Decreasing values of $\xi$ are obtained when $c_{\mathrm{T}, \mathrm{NTA}}$ increases, as noticed by comparing the values corresponding to $\operatorname{Exp} \mathrm{B}\left(c_{\mathrm{T}, \mathrm{NTA}}=1.14 \mathrm{mmol} \mathrm{L}^{-1}\right)$ with those of $\operatorname{Exp} A\left(c_{\mathrm{T}, \mathrm{NTA}}=5.50 \times 10^{-2} \mathrm{mmol} \mathrm{L}^{-1}\right)$ for a fixed configuration of the DGT devices. Theoretical expectations for $\xi$ obtained with numerical simulations (described in Section 3.6) are also gathered in Table 4 . Notice that the value $k_{\mathrm{d}, 1}$ fitted for the $1 \mathrm{R} 1 \mathrm{G}$ device deployed at $c_{\mathrm{T}, \mathrm{NTA}}=5.50 \times 10^{-2} \mathrm{mmol} \mathrm{L}^{-1}$ for the system with $c_{\mathrm{T}, \mathrm{NTA}}=$ $1.14 \mathrm{mmol} \mathrm{L}^{-1}$ has been used, since the rate dissociation constant is a physicochemical parameter independent of the ligand concentration. Equilibrium between $\mathrm{Ni}(\mathrm{NTA})_{2}$ and NiNTA was assumed as explained in Section 3.5. Moreover, the fitting of only one experimental parameter (the dissociation rate constant of the NiNTA complex) was enough for the interpretation of all the data reported in the manuscript, i. e., the data corresponding to the different DGT configurations (4) and to the different NTA concentrations (2), either with the formation of only NiNTA or the formation of both NiNTA and Ni(NTA $)_{2}$. The remarkable agreement between experimental and theoretical predictions lends support to the robustness of the developed model.

A simple analytical relationship between the lability degree and the physicochemical parameters in a system like the one with NiNTA and Ni $(\mathrm{NTA})_{2}$ can be helpful. The simple model $\mathrm{M}+\mathrm{L} \rightleftharpoons \mathrm{ML}$ does not account for this phenomenon, so a general theory for $\mathrm{ML}_{n}$ complexes would be useful.

As quoted above, in a set of successive complexes, the dissociation of ML into $\mathrm{M}$ and $\mathrm{L}$ is usually the rate limiting step (Morel and Hering, 1993; Puy et al., 2004). Accordingly, it is reasonable to assume that $\mathrm{ML}_{2}, \mathrm{ML}_{3}$, and successive complexes are in equilibrium with ML, but not with M if they are partially labile. These equilibrium relationships allow to reformulate the reaction-diffusion set of

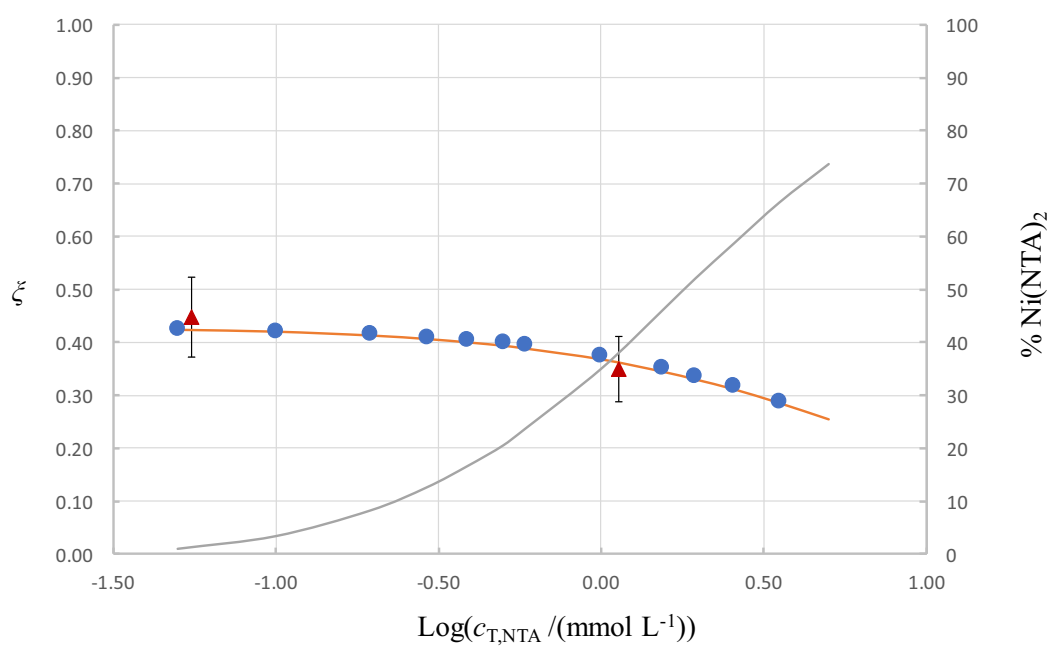

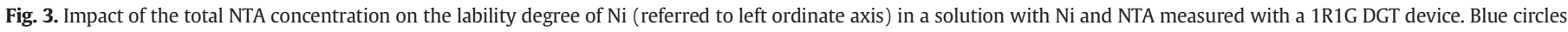

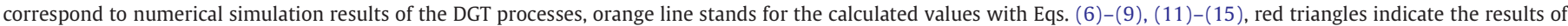

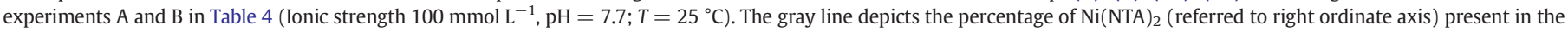
solution. Total Ni concentration and all the parameters as in Fig. 2. 
equations corresponding to the DGT processes in a scheme formally analogous to the case of only one complex of $1: 1$ metal-to-ligand stoichiometry (see SI). Labelling as $\mathrm{ML}_{\text {eff }}$ the effective (formal) complex, the reformulation of a system that only contains $M L$ and $\mathrm{ML}_{2}$ is reached by defining

$c_{\mathrm{ML}, \mathrm{eff}}^{*}=c_{\mathrm{ML}}^{*}+c_{\mathrm{ML}_{2}}^{*}$

$D_{\mathrm{ML}, \mathrm{eff}}=\frac{D_{\mathrm{ML}}+K_{2}^{\prime} D_{\mathrm{ML}_{2}}}{1+K_{2}^{\prime}}$

$k_{\mathrm{a}, \mathrm{eff}}^{\prime}=k_{\mathrm{a}, 1}^{\prime}$

$k_{\mathrm{d}, \mathrm{eff}}=k_{\mathrm{d}, 1} \frac{1}{1+K_{2}^{\prime}}$

$K_{\text {eff }}^{\prime}=K_{1}^{\prime}\left(1+K_{2}^{\prime}\right)$

$\Pi_{\mathrm{eff}}=\frac{c_{\mathrm{ML}, \mathrm{eff}}^{\mathrm{r}^{-}}}{c_{\mathrm{ML}, \mathrm{eff}}^{\mathrm{r}^{+}}}=\frac{\Pi^{z_{\mathrm{ML}}}+K_{2}^{\prime} \Pi^{z_{\mathrm{ML}}}}{1+K_{2}^{\prime}}$

where $K_{i}=\frac{k_{\mathrm{a}, i}}{k_{\mathrm{d}, i}}$ stands for the stability constant of the process $\mathrm{ML}_{i-1}+$ $\mathrm{L} \rightleftharpoons \mathrm{ML}_{i}, k_{\mathrm{a}, i}$ and $k_{\mathrm{d}, i}$ are the association and dissociation rate constants and $K_{i}^{\prime}=\frac{k_{\mathrm{a}, i} c_{\mathrm{L}}^{*}}{k_{\mathrm{d}, i}}=\frac{c_{\mathrm{ML}_{i}}^{*}}{c_{\mathrm{ML}_{i-1}}^{*}}$.

Eqs. (12), (14) and (15) have to be understood as "local" expressions, in the sense that the computation of the effective diffusion coefficient, dissociation rate constant and stability constant of this formal complex should use the corresponding values at the domain of interest (e.g. the diffusive gel or the resin). For instance, since the free ligand is electrically charged, the ligand concentration profile in excess of ligand conditions exhibits a discontinuity at the resin/diffusive gel interface $\left(x=\delta^{\mathrm{r}}\right)$. For $x>\delta^{\mathrm{r}}, c_{\mathrm{L}}(x)=c_{\mathrm{L}}^{*}$, while for $x<\delta^{\mathrm{r}}, c_{\mathrm{L}}(x)=c_{\mathrm{L}}^{\mathrm{R}}=\Pi^{z_{\mathrm{L}}} c_{\mathrm{L}}^{*}$. Thus, $K_{i}{ }^{\prime}$ takes different values in the diffusive gel or in the resin gel and accordingly, $K_{\text {eff }}$ 'given in (15) becomes

$K_{\text {eff }}^{\prime}=\left\{\begin{array}{c}K_{1}^{\prime}{ }^{\mathrm{R}}\left(1+\mathrm{K}_{2}^{\prime}{ }^{\mathrm{R}}\right)=\Pi^{\mathrm{z}_{\mathrm{L}}} \mathrm{K}_{1}^{\prime}\left(1+\Pi^{\mathrm{z}_{\mathrm{L}}} \mathrm{K}_{2}^{\prime}\right) \quad \mathrm{x}<\delta^{\mathrm{r}} \\ \mathrm{K}_{1}^{\prime}\left(1+\mathrm{K}_{2}^{\prime}\right) \quad \mathrm{x}>\delta^{\mathrm{r}}\end{array}\right.$

According to Eq. (14), in a system with $\mathrm{ML}$ and $\mathrm{ML}_{2}$, an increase of the ligand concentration not only shifts the equilibrium towards complexation, but also modifies the effective dissociation rate constant. Indeed, as Eq. (14) indicates, the effective dissociation rate constant decreases as the ligand concentration increases whenever

$K_{2}^{\prime}=K_{2} c_{\mathrm{L}}^{*}=\frac{c_{\mathrm{ML}}^{*}}{c_{\mathrm{ML}}^{*}}>1$

indicating that when $c_{\mathrm{ML} 2}^{*}>c_{\mathrm{ML}}^{*}$, i.e., when $\mathrm{ML}_{2}$ is the relevant species in the system, an increase in the ligand concentration reduces the lability degree of the system. This is a noticeable result in DGT, since it is a particular trait of $\mathrm{ML}_{n}$ complexes that contrasts with the almost negligible influence of the ligand concentration on the lability when only ML complexes arise (Puy et al., 2012).

The dissociation rate constant of the formal complex defined in Eq. (14) can be calculated in the diffusive gel domain from $K_{2}^{\prime}$ and $k_{\mathrm{d}, 1}$. For Exp B in (Table 1), it becomes $k_{\mathrm{d}, \text { eff }}=9.08 \times 10^{-4} \mathrm{~s}^{-1}$, so that $k_{\mathrm{d}, \text { eff }}<k_{\mathrm{d}, 1}$. It has to be highlighted that $k_{\mathrm{d}, \text { eff }}$ is not fitted from the experimental results, but derived from Eq. (14), so that all the experiments are interpreted with only one fitted parameter, $k_{\mathrm{d}, 1}$ as quoted above.

Using $k_{\mathrm{d}, \mathrm{eff}}$ Exp B can be interpreted as if there was a solution with only one complex instead of the two complexes NiNTA and Ni(NTA $)_{2}$. Thus, the lability degree in each DGT device in Exp B is calculated using expression (6) and the effective parameters given by Eqs. (11)(15). The resulting $\xi$-values, reported in the last row of Table 4 and as orange line in Fig. 3, indicate that the analytical expression (6) is consistent with experimental and simulated values (see red and blue markers in Fig. 3 respectively), paving the way to the use of a DGT device with different configurations to obtain information about dynamic speciation in natural systems.

Given the increase of the total NTA concentration, close to a factor of 100 , one could expect a stronger decrease. However, we have to notice that the decrease of the effective rate constant depends on $1+K_{2} C_{\mathrm{NTA}^{3-}}$ as Eq. (14) indicates. Taking into account the speciation of the system, as given by VMinteq, $K_{2} C_{\mathrm{NTA}^{3-}}$ keeps being smaller than 1 , so that there is only a mild decrease in $k_{\mathrm{d}, \text { eff. }}$. Actually, speciation of NTA is mainly dominated by HNTA at the $\mathrm{pH}$ of the experiment. Accordingly, only a mild decrease of the lability degree is observed in Table 4 when the NTA concentration increases and $\mathrm{Ni}(\mathrm{NTA})_{2}$ starts to be relevant as also seen in Fig. 3.

Additional insight on the effect of the total NTA concentration on the lability degree of the Ni complexes can be obtained looking at the concentration profiles. The concentration profile of $\mathrm{Ni}(\mathrm{NTA})_{2}$ is now included in Fig. 4, given the non-negligible concentration of this complex. Unlike the concentration profiles depicted in Fig. 2, the NTA concentration profile in Fig. 4 is almost flat indicating fulfilment of excess of ligand conditions, as expected from the increase of the total NTA by a factor of 50 . Discontinuities of the concentration profiles at $x=\delta^{\mathrm{r}}$ are in agreement with the electrostatic partitioning and, for each type of DGT device, the NiNTA concentration at $x=\delta^{r^{+}}$is in Fig. 4 higher than in Fig. 2, consistent with the lower lability degree in the conditions of Fig. 4.

A main difference between the concentration profiles in Figs. 2 and 4 is the overlapping of normalized concentration profiles of Ni and NiNTA along most of the diffusion gel domain. In excess ligand conditions this overlapping indicates equilibrium (Salvador et al., 2006a; Salvador et al., 2006b; Zhang et al., 2011; Zhang and Buffle, 2009). The diverging of both normalized profiles defines the reaction layer, where net dissociation takes place. Moreover, the normalized NiNTA concentration profile converges with that of $\mathrm{Ni}(\mathrm{NTA})_{2}$ in all the diffusive gel domain, indicating that both complexes are in equilibrium, as expected from assuming that the dissociation of NiNTA is the rate limiting dissociation step. Thus, according to Eq. (4), the particular lability degrees of both complexes coincide and also coincide with the lability degree of the full system, since it can be shown (see Eq. (8) in reference (Uribe et al., 2013)) that the last one is a weighted average of the particular lability degrees of the present complexes. The particular lability degree of a complex is not usually measurable. However, in excess of ligand conditions, the lability degree of successive complexes in equilibrium with ML can be measured, since all these complexes have a common lability degree which coincides with that of the system.

In Fig. 2, the existing equilibrium between some Ni species (in some regions) does not show up as a collapse of the concentration profiles (of the species in equilibrium), due to the system not being under ligand excess conditions.

The dependence of the lability degree on the thickness of the diffusive gel or of the resin follows the same trend commented in the above section and for the same reasons.

Almost all transition metals yield $\mathrm{ML}_{n}$ complexes with simple ligands due to the high number of possible bonds in the coordination sphere and almost all of these ligands are involved in acid-base equilibria. Thus, the effects commented above are of a broad applicability to most of the trace metal complexes. As general conclusion, the model here developed suggests that lability decreases as the ligand-to-metal ratio increases, i.e., as the ligand-to-metal stoichiometry $(n)$ of the dominant species increases.

\section{Conclusions}

Speciation in natural systems is challenging since many measurements involve the contribution of multiple species through several 

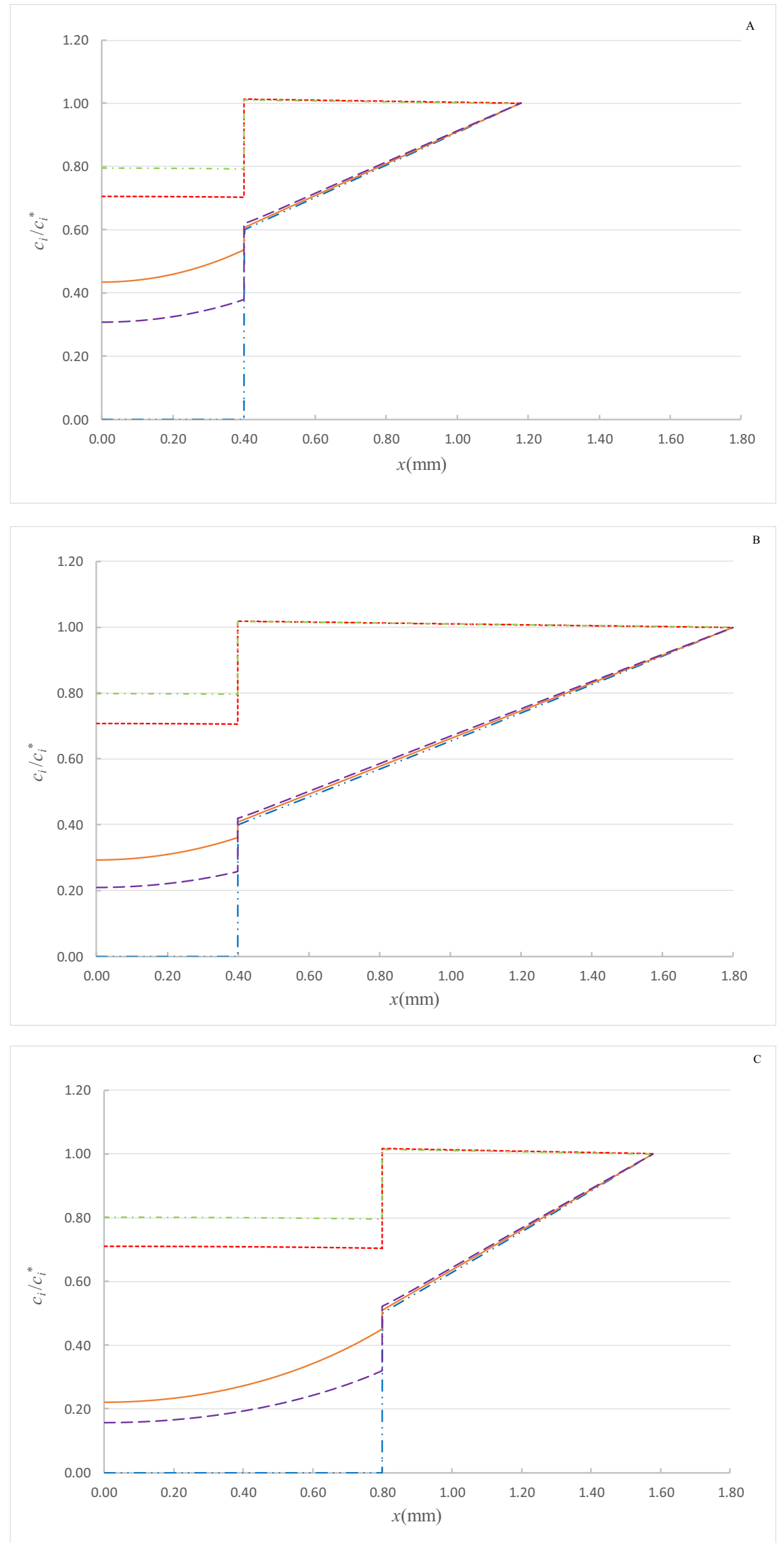

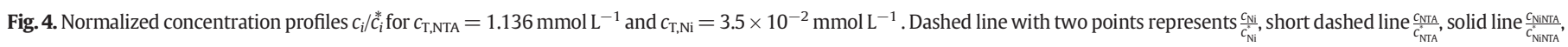
dashed line with one point $\frac{c_{\mathrm{HNTA}}}{c_{\mathrm{HNIA}}^{*}}$ and long dashed line $\frac{c_{\mathrm{Ni}(\mathrm{NTA})_{2}}}{\bar{c}_{\mathrm{Ni}(\mathrm{NTA})_{2}}}$. Rest of parameters as in Fig. 2. 
physicochemical parameters. Accordingly, a set of independent measurements and a suitable theoretical framework is required to solve the speciation unless more selective analytical techniques were developed. Based on using a set of DGT devices with different resin or diffusive gel thicknesses, this work paves the way to optimize the correlation between chemical composition and bioavailability, as well as it lays out a framework to solve the speciation and labilities of complexes present in natural samples.

It is shown that the lability degree increases as the thickness of either the diffusive gel or the resin disc of the DGT device increases. A simple analytical expression is shown to reproduce accurately this dependence in excess of ligand condition as usually met in trace metal analysis. Defining effective concentrations and parameters, this expression can be extended to systems with sequential complexation. In this case, an increase of the ligand concentration tends to decrease the lability degree of the system due to a decrease of the effective dissociation rate constant. The decrease of the lability degree is more evident when, following the increase of the ligand concentration, the main complex present in the solution moves from ML to $\mathrm{ML}_{n}$. Only the fitting of the dissociation rate constant of ML is required for the interpretation of the lability of the $\mathrm{ML}_{n}$ system with any DGT configuration.

\section{CRediT authorship contribution statement}

Jordi Sans-Duñó: Data curation, Formal analysis, Writing - original draft. Joan Cecilia: Software. Josep Galceran: Conceptualization, Writing - review \& editing. Jaume Puy: Supervision, Conceptualization, Writing - review \& editing.

\section{Declaration of competing interest}

The authors declare that they have no known competing financial interests or personal relationships that could have appeared to influence the work reported in this paper.

\section{Acknowledgements}

Support from the Spanish Minister of Science and Innovation is gratefully acknowledged (Project PID2019-107033GB-C21). JSD acknowledges the University of Lleida for a fellowship PhD contract.

\section{Appendix A. Supplementary data}

Supplementary data to this article can be found online at https://doi. org/10.1016/j.scitotenv.2021.146277.

\section{References}

Altier, A., 2018. Diffusive Gradients in Thin-Films (DGT) Beyond Perfect Sink Conditions, $\mathrm{PhD}$ Thesis. (PhD thesis). Universitat de Lleida.

Altier, A., Jimenez-Piedrahita, M., Rey-Castro, C., Cecilia, J., Galceran, J., Puy, J., 2016. Accumulation of Mg to diffusive gradients in thin films (DGT) devices: kinetic and thermodynamic effects of the ionic strength. Anal. Chem. 88, 10245-10251.

Altier, A., Jimenez-Piedrahita, M., Uribe, R., Rey-Castro, C., Cecilia, J., Galceran, J., et al., 2018. Effects of a mixture of ligands on metal accumulation in diffusive gradients in thin films (DGT). Environ. Chem. 15, 183-193.

Baeyens, W., Gao, Y., Davison, W., Galceran, J., Leermakers, M., Puy, J., et al., 2018. In situ measurements of micronutrient dynamics in open seawater show that complex dissociation rates may limit diatom growth. Sci. Rep. 8.

Bakker, E., Pretsch, E., 2007. Modern potentiometry. Angewandte Chemie-International Edition. vol. 46, pp. 5660-5668.

Canovas, C.R., Basallote, M.D., Borrego, P., Milian-Becerro, R., Perez-Lopez, R., 2020. Metal partitioning and speciation in a mining-impacted estuary by traditional and passive sampling methods. Sci. Total Environ. 722.

Cindric, A.M., Marcinek, S., Garnier, C., Salaun, P., Cukrov, N., Oursel, B., et al., 2020. Evaluation of diffusive gradients in thin films (DGT) technique for speciation of trace metals in estuarine waters - a multimethodological approach. Sci. Total Environ. 721.

Companys, E., Galceran, J., Puy, J., Sedo, M., Vera, R., Antico, E., et al., 2018. Comparison of different speciation techniques to measure $\mathrm{Zn}$ availability in hydroponic media. Anal. Chim. Acta 1035, 32-43.
Davison, W., Zhang, H., 1994. In-situ speciation measurements of trace components in natural waters using thin-film gels. Nature 367, 546-548.

Galceran, J., Puy, J., 2015. Interpretation of diffusion gradients in thin films (DGT) measurements: a systematic approach. Environ. Chem. 12, 112-122.

Galceran, J., Puy, J., Salvador, J., Cecília, J., van Leeuwen, H.P., 2001. Voltammetric lability of metal complexes at spherical microelectrodes with various radii. J. Electroanal. Chem. 505, 85-94.

Gao, Y., Zhou, C.Y., Gaulier, C., Bratkic, A., Galceran, J., Puy, J., et al., 2019. Labile trace metal concentration measurements in marine environments: from coastal to open ocean areas. Trac-Trends Anal. Chem. 116, 92-101.

Gramlich, A., Tandy, S., Slaveykova, V.I., Duffner, A., Schulin, R., 2012. The use of permeation liquid membranes for free zinc measurements in aqueous solution. Environ. Chem. 9, 429-437.

Gustafsson, J.P., 2016. Visual MINTEQ version 3.1. https://vminteq.lwr.kth.se/download/.

Huang, J.Y., Bennett, W.W., Welsh, D.T., Li, T.L., Teasdale, P.R., 2016. “Diffusive gradients in thin films" techniques provide representative time-weighted average measurements of inorganic nutrients in dynamic freshwater systems. Environ. Sci. Technol. 50, 13446-13454.

Jimenez-Piedrahita, M., Altier, A., Cecilia, J., Rey-Castro, C., Galceran, J., Puy, J., 2015 Influence of the settling of the resin beads on diffusion gradients in thin films measurements. Anal. Chim. Acta 885, 148-155.

Lao, M., Companys, E., Weng, L., Puy, J., Galceran, J., 2018. Speciation of Zn, Fe, Ca and Mg in wine with the Donnan membrane technique. Food Chem. 239, 1143-1150.

Levy, J.L., Zhang, H., Davison, W., Galceran, J., Puy, J., 2012a. Kinetic signatures of metals in the presence of Suwannee River fulvic acid. Environ. Sci. Technol. 46, 3335-3342.

Levy, J.L., Zhang, H., Davison, W., Puy, J., Galceran, J., 2012b. Assessment of trace metal binding kinetics in the resin phase of diffusive gradients in thin films. Anal. Chim. Acta $717,143-150$

Menegario, A.A., Yabuki, L.N.M., Luko, K.S., Williams, P.N., Blackburn, D.M., 2017. Use of diffusive gradient in thin films for in situ measurements: a review on the progress in chemical fractionation, speciation and bioavailability of metals in waters. Anal. Chim. Acta 983, 54-66.

Mikkelsen, O., van den Berg, C.M.G., Schroder, K.H., 2006. Determination of labile iron at low nmol L-1 levels in estuarine and coastal waters by anodic stripping voltammetry. Electroanalysis 18, 35-43.

Mohan, C., 2003. Buffers. A guide for the preparation and use of buffers in biological systems. In: Merck, C. (Ed.), Darmstadt (D).

Mongin, S., Uribe, R., Puy, J., Cecilia, J., Galceran, J., Zhang, H., et al., 2011. Key role of the resin layer thickness in the lability of complexes measured by DGT. Environ. Sci. Technol. 45, 4869-4875.

Morel, F.M.M., Hering, J.G., 1993. Complexation. Principles and Applications of Aquatic Chemistry. vol. 197. John Wiley, New York, pp. 319-420.

Noel, S., Tercier-Waeber, M.L., Lin, L., Buffle, J., 2003. Complexing gel integrated microelectrode arrays for direct detection of free metal ion concentrations in natural waters. J. Phys. IV 107, 965-968.

Parat, C., Pinheiro, J.P., 2015. ISIDORE, a probe for in situ trace metal speciation based on Donnan membrane technique with related electrochemical detection part 1: equilibrium measurements. Anal. Chim. Acta 896, 1-10.

Parthasarathy, N., Pelletier, M., Buffle, J., 2003. The use of Permeation Liquid Membrane (PLM) as an analytical tool for trace metal speciation studies in natural waters. J. Phys. IV 107, 1021-1024.

Pommier, A.L., Buzier, R., Simon, S., Guibaud, G., 2021. Impact of low ionic strength on DGT sampling with standard APA gels: effect of pH and analyte. Talanta 222.

Puy, J., Galceran, J., 2017. Theoretical aspects of dynamic metal speciation with electrochemical techniques. Curr. Opin. Electrochem. 1, 80-87.

Puy, J., Cecília, J., Galceran, J., Town, R.M., van Leeuwen, H.P., 2004. Voltammetric lability of multiligand complexes. The case of ML2. J. Electroanal. Chem. 571, 121-132.

Puy, J., Uribe, R., Mongin, S., Galceran, J., Cecilia, J., Levy, J., et al., 2012. Lability criteria in diffusive gradients in thin films. J. Phys. Chem. A 116, 6564-6573.

Puy, J., Galceran, J., Cruz-Gonzalez, S., David, C.A., Uribe, R., Lin, C., et al., 2014. Metal accumulation in DGT: impact of ionic strength and kinetics of dissociation of complexes in the resin domain. Anal. Chem. 86, 7740-7748.

Puy, J., Galceran, J., Rey-Castro, C., 2016. Interpreting the DGT measurement: speciation and dynamics. In: Davison, W. (Ed.), Diffusive Gradients in Thin-Films for Environmental Measurements. Cambridge University Press, Cambridge, pp. 93-122.

Salvador, J., Garcés, J.L., Galceran, J., Puy, J., 2006a. Lability of a mixture of metal complexes under steady-state planar diffusion in a finite domain. J. Phys. Chem. B 110, 13661-13669.

Salvador, J., Puy, J., Cecilia, J., Galceran, J., 2006b. Lability of complexes in steady state finite planar diffusion. J. Electroanal. Chem. 588, 303-313.

Scally, S., Davison, W., Zhang, H., 2006. Diffusion coefficients of metals and metal complexes in hydrogels used in diffusive gradients in thin films. Anal. Chim. Acta 558, 222-229.

Shiva, A.H., Teasdale, P.R., Bennett, W.W., Welsh, D.T., 2015. A systematic determination of diffusion coefficients of trace elements in open and restricted diffusive layers used by the diffusive gradients in a thin film technique. Anal. Chim. Acta 888, 146-154.

Temminghoff, E.J.M., Plette, A.C.C., van Eck, R., van Riemsdijk, W.H., 2000. Determination of the chemical speciation of trace metals in aqueous systems by the Wageningen Donnan Membrane Technique. Anal. Chim. Acta 417, 149-157.

Uribe, R., Mongin, S., Puy, J., Cecilia, J., Galceran, J., Zhang, H., et al., 2011. Contribution of partially labile complexes to the DGT metal flux. Environ. Sci. Technol. 45, 5317-5322.

Uribe, R., Puy, J., Cecilia, J., Galceran, J., 2013. Kinetic mixture effects in diffusion gradients in thin films (DGT). Phys. Chem. Chem. Phys. 15, 11349-11355. 
van Leeuwen, H.P., Town, R.M., Buffle, J., Cleven, R., Davison, W., Puy, J., et al., 2005. Dynamic speciation analysis and bioavailability of metals in Aquatic Systems. Environ. Sci. Technol. 39, 8545-8585.

Vera, R., Fontas, C., Galceran, J., Serra, O., Antico, E., 2018. Polymer inclusion membrane to access Zn speciation: comparison with root uptake. Sci. Total Environ. 622, 316-324.

Warnken, K.W., Davison, W., Zhang, H., 2008. Interpretation of in situ speciation measurements of inorganic and organically complexed trace metals in freshwater by DGT. Environ. Sci. Technol. 42, 6903-6909.

Worms, I., Simon, D.F., Hassler, C.S., Wilkinson, K.J., 2006. Bioavailability of trace metals to aquatic microorganisms: importance of chemical, biological and physical processes on biouptake. Biochimie 88, 1721-1731.

Yezek, L.P., van Leeuwen, H.P., 2005. Donnan effects in the steady-state diffusion of metal ions through charged thin films. Langmuir 21, 10342-10347.
Zhang, Z.S., Buffle, J., 2009. Interfacial metal flux in ligand mixtures. 1. The revisited reaction layer approximation: theory and examples of applications. J. Phys. Chem. A 113, 6562-6571.

Zhang, Z.S., Alemani, D., Buffle, J., Town, R.M., Wilkinson, K.J., 2011. Metal flux through consuming interfaces in ligand mixtures: boundary conditions do not influence the lability and relative contributions of metal species. Phys. Chem. Chem. Phys. 13, 17606-17614.

Zhao, J.J., Cornett, R.J., Chakrabarti, C.L., 2020. Assessing the uranium DGT-available fraction in model solutions. J. Hazard. Mater. 384 